\title{
DETEKSI POLISI TIDUR PADA JALAN MENGGUNAKAN ANILISIS BLOB DAN KONVOLUSIONAL NEURAL NETWORK
}

\author{
Ervin Indra Nugraha, Informatika Institut Sains dan Teknologi Terpadu Surabaya(ISTTS), \\ Yuliana Melita Pranoto, Informatika Institut Sains dan Teknologi Terpadu Surabaya(ISTTS).
}

\begin{abstract}
Abstrak- Polisi tidur merupakan pembatas kecepatan laju dari kendaraan yang sengaja ditempatkan diatas jalan. Polisi tidur memiliki dua jenis karakteristi. Polisi tidur memiliki ukuran berbeda yang ditemui pada beberapa perumahan, ditempat ujian sim, dan yang sering dijumpai pada perumahan atau jalan dengan beragam warna yang berbeda. Deteksi polisi tidur pada jalan akan menggunakan dua metode Anilisis blob dan CNN. Proses deteksi polisi tidur akan dilakukan menggunakan anilisis blob, saat metode anilisis blob tidak mendeteksi adanya polisi tidur maka akan dilakukan proses CNN untuk melakukan deteksi. Dalam proses anilisis blob, alur penelitian deteksi akan dilakukan menggunakan anilisis blob, pada saat proses blob tidak mendeteksi adanya polisi tidur maka proses deteksi akan dilanjutkan menggunakan CNN. Sebelum dilakukan proses deteksi menggunakan blob, gambar atau video frame akan diproses menggunakan proses preprosesing, morfologi erosi dan dilasi. Penggunaan proses preprosesing dan morfologi dilakukan agar objek berupa polisi tidur dapat dipisahkan dari gambar background yaitu aspal. Uji coba pada penelitian akan dilakukan pada 10 buah video dengan durasi minimal 30 detik dan 100 gambar polisi tidur yang diproses pada dataset. Pada dataset akan dikelompokan untuk dilakukan klasifikasi yaitu berwarna dan tidak berwarna. Setiap warna polisi tidur yang terdeteksi akan dicatat dan berapa banyak pada warna tersebut polisi tidur dapat dideteksi. Kedua metode yang digabungkan mendapatkan hasil deteksi yang baik dengan hasil $\mathbf{7 6 \%}$ terhadap polisi tidur pada perumahan. Pada uji coba rata-rata polisi tidur tanpa warna atau warna yang sama dengan aspal dan penggunaan paving pada jalan mempengaruhi tingkat akurasi dari deteksi polisi tidur.
\end{abstract}

Kata Kunci-Anilisis blob, CNN, Deteksi Polisi Tidur, Polisi tidur.

\section{Pendahuluan}

$\mathrm{P}$ olisi tidur digunakan untuk mengkontrol kecepatan dari kendaraan yang bergerak dijalan, hal tersebut dilakukan untuk membatasi kecepatan dari kendaraan yang melaju sehingga tidak terjadinya kecelakaan yang tidak diharapkan. Pengguna kendaraan kadang juga tidak memperhatikan adanya polisi tidur yang berada dijalan saat mengendarai dengan kecepatan yang tinggi. Adanya polisi tidur membuat pengendara kendaraan memperlambat laju dari kendaraan yang dibawa. Polisi tidur memiliki beberapa ukuran standard yang digunakan untuk tempat tertentu.[1]. Polisi tidur yang dideteksi pada jalanan India memiliki warna yang berbeda. Penelitian banyak dilakukan dijalanan India, dan dilakukan pada 5 kategori polisi tidur sesuai dengan jalan[1].

Ervin Indra Nugraha, Teknologi Informasi, Institut Sains dan Teknologi Terpadu Surabaya, Surabaya, Jawa Timur, Indonesia (email: ervinindra1@gmail.com).

Yuliana Melita Pranoto, Teknologi Informasi, Institut Sains dan Teknologi Terpadu Surabaya, Surabaya, Jawa Timur, Indonesia (email:ymp@stts.edu). warna putih kuning, kuning hitam, putih hitam dan tanpa warna. Sampel dari setiap kategori antara lain 300 untuk polisi putih kuning, 200 untuk polisi tidur kuning hitam, 200 untuk polisi tidur hitam, 150 untuk polisi tidur putih hitam, dan 150 untuk polisi tidur tanpa warna. Dari 5 kategori tersebut dapat disimpulkan deteksi polisi tidur menggunakan anilisis blob memiliki tingkat akurasi mencapai 80\%[1].

Berdasarkan hasil penelitian, anilisis blob memiliki kemampuan yang baik dalam mendeteksi gambar $2 \mathrm{D}$. Penelitian anilisis blob dapat dipadukan dengan proses segmentasi citra lain seperti Gaussian Filtering[2]. Pada penelitian telah mempertimbangkan 4 parameter untuk menentukan kinerja sistem pada tabel hasil analissa. Parameter tersebut antara lain True Positif, True Negatif, False Positive, dan False Negative. Hasil analisis dari tiap kategori, yaitu pada kategori 1, 2, 3 dan 4 nilai true positif hampir $90 \%$ pada tingkat keakurasian deteksi, sedangkan pada kategori 5 yang mendapatkan hasil yang lebih sedikit.

Pada negara berkembang infrastruktur dan keterbatasan sumber daya membuat negara menderita kondisi jalan yang buruk [3]. Deteksi pada hambatan pada negara berkembang dapat dilakukan menggunakan CNN. Dalam pengujian, model CNN dapat mendeteksi objek yang diinginkan, yaitu lubang pada jalan dan polisi tidur dengan akurasi tinggi. Akurasi pada lubang jalan dengan nilai paling tinggi $99 \%$ dan paling rendah adalah $95 \%$ sedangkan pada polisi tidur dengan nilai $99 \%$.

Menurut Sandeep Shaah [4] penggunaan CNN terhadap deteksi polisi tidur dapat membantu untuk mengurangi kecelakaan yang terjadi dalam berkendara dijalan. penelitian dilakukan menggunakan dashcam, Pada penelitian diharapkan sebuah langkah untuk mengurangi jumlah kecelakaan. Penelitian menggunakan transfer learning yang digunakan pada data yang telah dilatih menggunakan jaringan saraf dengan memodifikasi layer klasifikasi. Jaringan saraf akan melakukan training dan melakukan klasifikasi pada data dengan jumlah 1000 atau lebih yang akan dilakukan selama beberapa minggu. Hasil Klasifikasi dengan network memiliki hasil true positif $88.9 \%$.

Pada pengembangan penelitian lainnya, deteksi pada polisi tidur dapat dikembangkan ketingkat yang lebih tinggi yaitu advance driver assistance [5]. Pada penelitian menghasilkan nilai rata-rata $80 \%$ pada polisi tidur berwarna dan $4 \%$ pada polisi tidur tanpa warna.

Berdasarkan dari penelitian yang telah ada [6]-[15], anilisis blob dapat secara baik mendeteksi polisi tidur yang memiliki warna yang jelas. Tujuan dari penelitian ini adalah menggabungkan anilisis blob dengan CNN sehingga deteksi polisi tidur dapat lebih efektif untuk mendeteksi polisi tidur berwarna atau tidak berwarna. 


\section{Metodologi Penelitian}

Pada penelitian menggunakan 2 metode yang digunakan untuk mendeteksi polisi tidur. Dua metode penelitian digunakan untuk melengkapi deteksi sistem dimana metode blob analisi memiliki kelemahan dalam medeteksi gambar polisi tidur tanpa warna. Metode pertama merupakan deteksi menggunakan anilisis blob, dimana deteksi dari input gambar ataua video akan dideteksi pixel- pixel yang berhubungan untuk mencari sebuah objek yang telah ditentukan pada penelitian yaitu polisi tidur. Metode kedua merupakan convolutional neural network (CNN), dimana deteksi input gambar atau video akan dideteksi menggunakan metode machine learning. Dibutuhkan dataset untuk menggunakan teknik machine learning convolutional neural network. Pembagian alur penelitian akan dijabarkan beberapa proses. Proses dari alur sistem antara lain proses frame ekstraksi, proses preprosesing, proses thresholding, proses morphologi yaitu meliputi erosi dan dilasi, proses anilisis blob dan proses convolutional neural network. Alur penelitian dapat dilihat pada gambar 1.

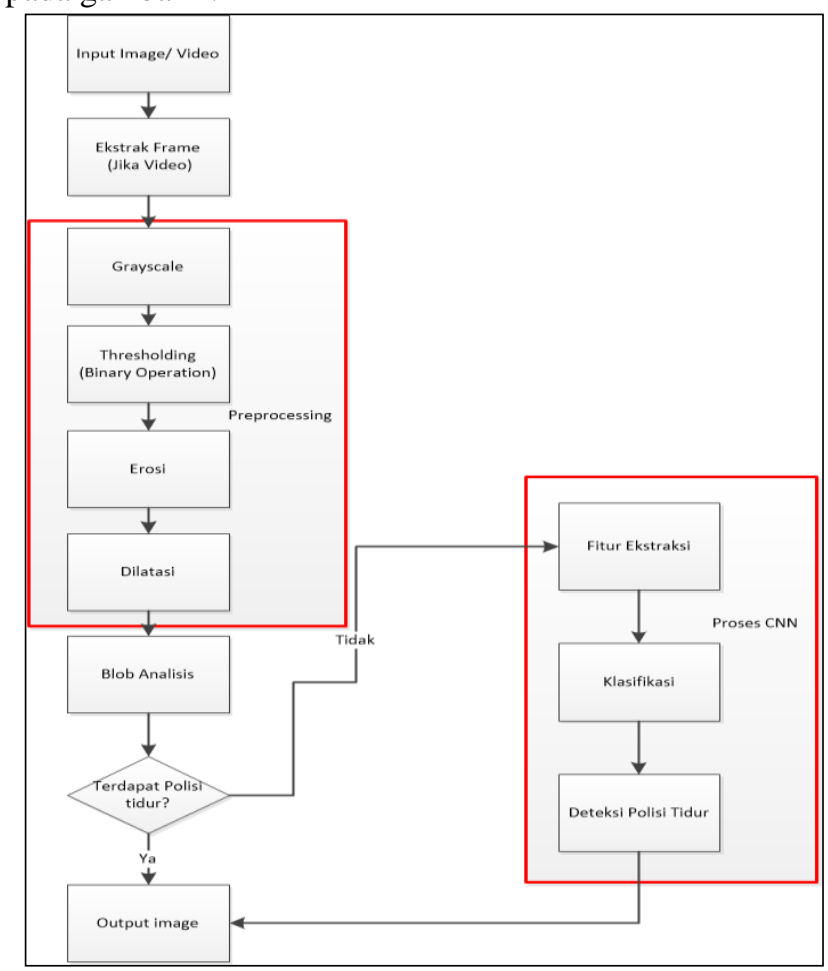

Gambar. 1. Alur Penelitian Deteksi

\section{A. Ekstrak Frame}

Pada tahap pertama penelitian, input pada penelitian dibagi menjadi dua yaitu video dan gambar. Deteksi pada tahap pertama akan dilakukan menggunakan metode anilisis blob dimana input akan berupa gambar yang akan dilakukan proses untuk mendeteksi objek polisi tidur pada gambar.

\section{B. Proses Grayscale dan Masking}

Pada tahap preperocessing input gambar merupakan input yang berasal dari proses frame ekstraksi, jika input merupakan gambar maka proses ektraks frame akan dilewati dan gambar akan langsung diproses pada proses preprosesing. Gambar akan diubah menjadi gambar dalam warna grayscale. Gambar akan diubah menjadi grayscale dengan persamaan 2 .
Grayscale $=(0.3 * R)+(0.59 * G)+(0.11 * B)$

Pada persamaan 2 dapat dijelaskan dimana $\mathrm{R}$ adalah nilai intensitas warna pixel merah pada gambar, $G$ adalah nilai intensitas warna pixel hijau gambar, B adalah nilai intensitas warna pixel biru pada gambar. Pada perhitungan grayscale tiap warna pada masing - masing pixel akan dirubah. Warna keseluruhan pada gambar yang terbentuk akan dinormalisasi oleh persamaan grayscale sehingga warna yang dihasilkan pada gambar menjadi berwarna abu- abu. Hasil grayscale dapat dilihat pada gambar 2 .

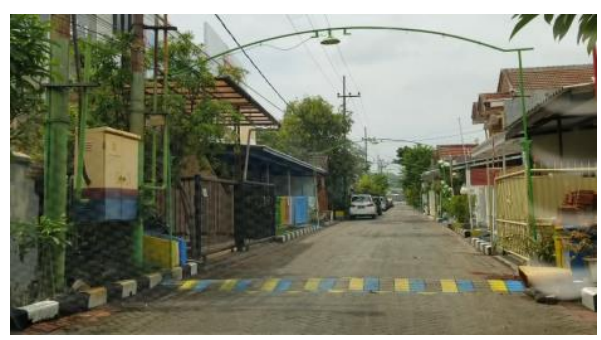

(a)

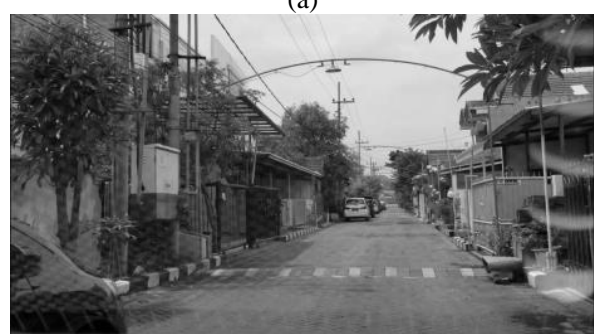

(b)

Gambar. 2. (a)Gambar input (b) gambar hasil grayscale

Pada gambar 2(b) merupakan hasil grayscale dari gambar input dari penelitian. Pada gambar grayscale merubah warna RGB menjadi keabuan yang digunakan untuk mereduksi noise warna pada gambar input. Noise pada gambar direduksi dengan tujuan agar warna yang tidak dibutuhkan tidak ikut diproses pada proses selanjutnya sehingga tidak memperberat dan memakan banyak resource yang dibutuhkan. Gambar dengan noise yang cenderung banyak membuat deteksi pada anilisis blob menjadi tidak baik dan akurat. Pada proses grayscale dilakukan agar gambar menjadi siap untuk dilakukan proses lebih lanjut untuk dilakukan adanya deteksi.

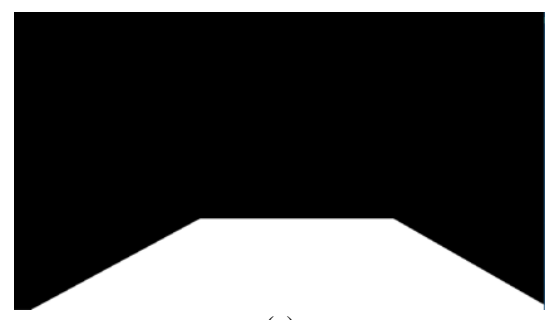

(a)

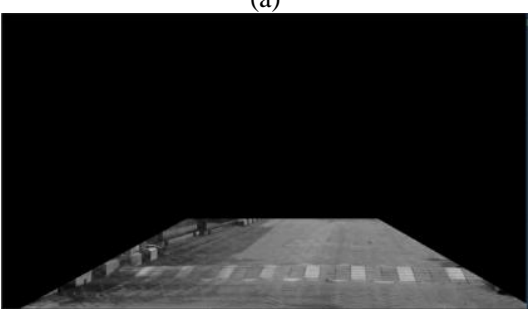

(b)

Gambar. 3. (a)Masking yang digunakan (b) gambar hasil masking 
Pada proses grayscale akan dilakukan proses masking untuk mendeteksi polisi tidur. Masking pada gambar grayscale dilakukan pada posisi jalan bagian bawah dimana polisi tidur tertangkap kamera smartphone. Proses Masking bertujuan agar proses selanjutnya pada penelitian akan memproses gambar jalan yang memiliki polisi tidur saja dan bukan gambar mobil atau pohon. Hasil masking dapat dilihat pada gambar 3.

\section{Proses Thresholding}

Pada proses thresholding, gambar hasil dari proses masking pada gambar 6(b) akan dilakukan proses thresholding dimana warna pixel yang gelap akan diubah menjadi hitam dan warna yang lebih terang akan diubah menjadi putih. Persamaan thresholding dapat dilihat pada persamaan 3.

$g_{(x, y)}=\left\{\begin{array}{l}1, f_{(x, y)}>T \\ 0, f_{(x, y)} \leq T\end{array}\right.$

pada thresholding bertujuan untuk mengekstrak objek dari background gambar. Patern dari objek yang akan dideteksi akan lebih nampak pada gambar setelah proses thresholding dilakukan. Hasil thresholding ditunjukan pada gambar 4.

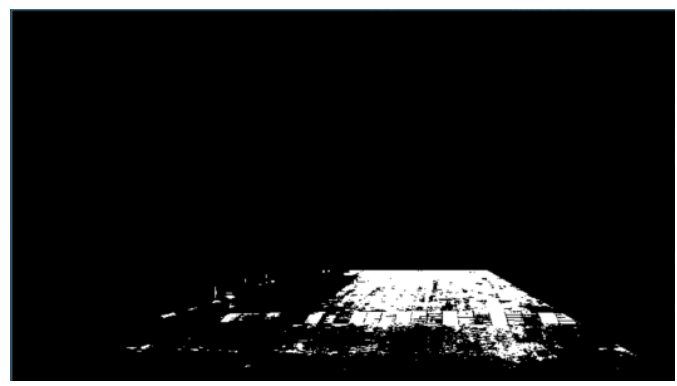

Gambar. 4. Hasil Proses Thresholding

\section{Proses Erosi dan Dilasi}

Pada proses erosi, pixel pada gambar hasil thresholding akan direduksi atau dikikis untuk menghilangkan noise. Tujuan proses erosi dilakukan agar bentuk objek yang merupakan polisi tidur dapat terlihat dengan jelas pada gambar, sedangkan objek lain yang ikut terekstrak saat proses thresholding dapat menghilang.

Reduksi yang dilakukan pada pixel gambar berwarna putih. Hasil dari penggunaan erosi terhadap gambar hasil thresholding dapar dilihat pada gambar 5 .

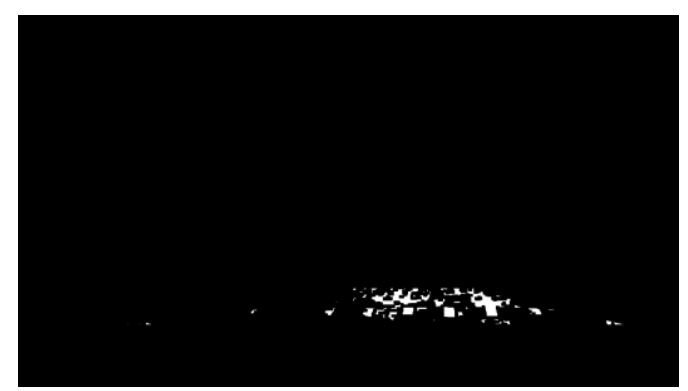

Gambar. 5. Hasil Erosi

Setelah dilakukan proses erosi, maka akan dilakukan proses dilasi. Proses dilasi merupakan kebalikan dari proses erosi. Dilasi akan melakukan penebalan terhadap pixel gambar berwarna putih, sehingga objek yang dideteksi akan terlihat lebih jelas pada gambar. Objek yang telah direduksi pixelnya pada proses erosi tidak akan tampil saat gambar dilakukan proses dilasi karena pixel objek telah tereduksi. Pada tahap dilasi gambar pixel dapat digunakan sebagai objek yang akan diproses menggunakan anilisis blob apakah objek tersebut polisi tidur atau bukan. Berikut hasil dilasi dapat dilihat pada gambar 6 .

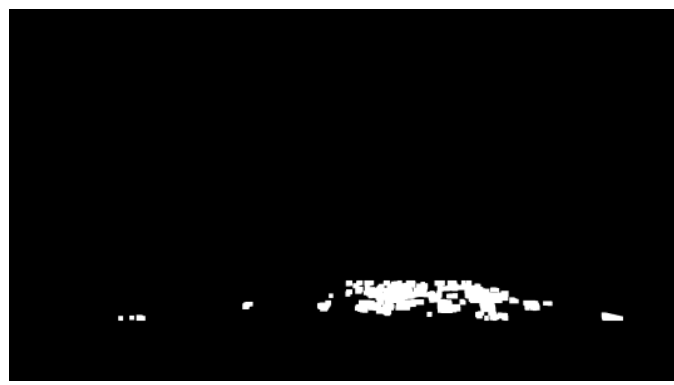

Gambar. 6. Hasil Dilasi

\section{E. Anilisis Blob}

Pada tahap setelah preprosessing adalah tahap anilisis blob. Pada tahap anilisis blob gambar akan dilakukan deteksi apakah terdapat objek polisi tidur pada gambar atau tidak. Input pada deteksi anilisis blob merupakan output dari morpologi dilasi. Pada gambar yang terdapat objek polisi tidur akan dilakukan penandaan letak dari polisi tidur yang ditemukan.

Pada Penelitian anilisis blob yang digunakan untuk menentukan adanya polisi tidur pada jalan. Input gambar pada anilisis blob merupakan gambar dengan tipe binary, yaitu gambar dengan warna hitam dan putih. Berikut merupakan persamaan matrix gambar yang digunakan dalam anilisis blob pada penelitian dilihat pada persamaan 4 .

$$
H(x, \sigma)=\left[\begin{array}{ll}
L_{x x}(x, \sigma) & L_{x y}(x, \sigma) \\
L_{x y}(x, \sigma) & L_{y y}(x, \sigma)
\end{array}\right]
$$

Pada persamaan $4 H_{(x, \sigma)}$ merupakan symbol dari hessian matrix pada titik $\mathrm{x}$ pada skala $\sigma$. Pada titik yang dilambangkan $\mathrm{x}$ memiliki koordinat pada $\mathrm{x}$, y pada gambar yang akan dideteksi. Pada persamaan $4 L_{x x}(x, \sigma)$ merupakan hasil nilai perkalian terhadap titik $\mathrm{x}$, pada titik $\mathrm{xy}$, dan terhadap titik y. Pada hasil persamaan 4 , hessian matrix akan menghasilkan matrix dari gambar yang diinputkan. Matrix yang dihasilkan pada persamaan 4.1 akan dikalikan dengan Gaussian kernel yang akan menghasilkan matrix $3 \times 3$ dimana hasil matrix merupakan koordinat dari titik $\mathrm{x}$, koordinat dari titik y, dan ukuran blob pada titik tersebut.

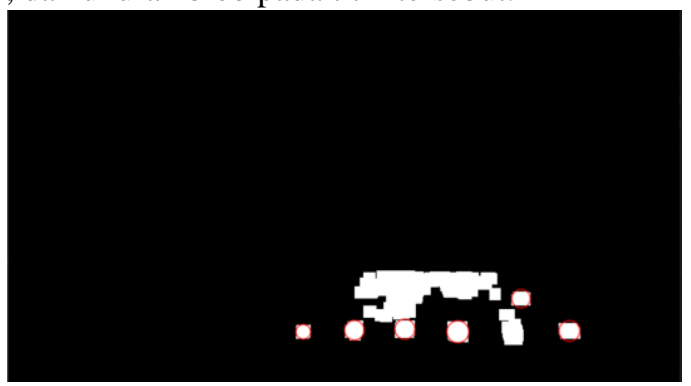

Gambar. 7. Hasil Blob 
Pada gambar 7 merupakan hasil anilisis blob, pada pixel putih bertanda label lingkaran merah merupakan blob yang dideteksi pada penelitian. Pixel putih dengan lingkaran merah ditandai berdasarkan titik koordinat blob yang ditemukan pada gambar. Hasil yang ditunjukan pada blob akan disimpan dan diambil titik koordinatnya untuk digambarkan tanda pada letak polisi tidur pada gambar RGB. Hasil pelabelan dapat dilihat pada gambar 8 .

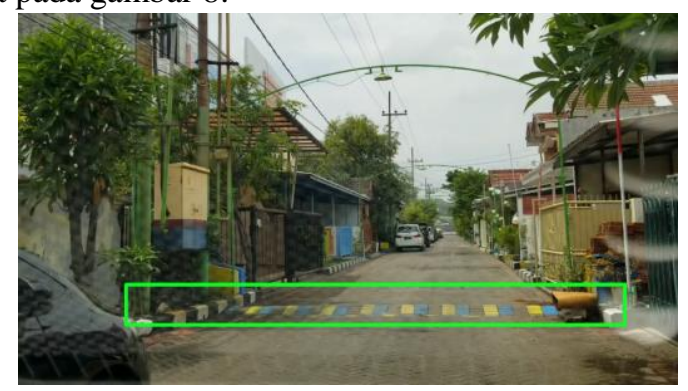

Gambar. 8. Hasil Deteksi Polisi Tidur

\section{F. Input Pada CNN}

Input pada CNN merupakan frame video atau gambar berwarna dari frame ekstraksi. Pada hasil gambar yang didapat dari frame ekstraksi akan ditampung pada dua variabel berbeda. Pada variabel pertama gambar akan diproses menggunakan proses preprosessing, dan diteruskan pada analisis blob. Saat analisis blob tidak menemukan adanya polisi tidur maka variabel kedua yang berisi gambar RGB akan diteruskan pada proses CNN untuk dideteksi.

\section{G. Convolutional Neural Network (CNN)}

Pada tahap CNN, jika polisi tidur tidak dapat dideteksi menggunakan anilisis blob, maka CNN akan mendeteksi gambar input pada penelitian. Gambar arsitektur CNN dapat dilihat pada gambar 9 .

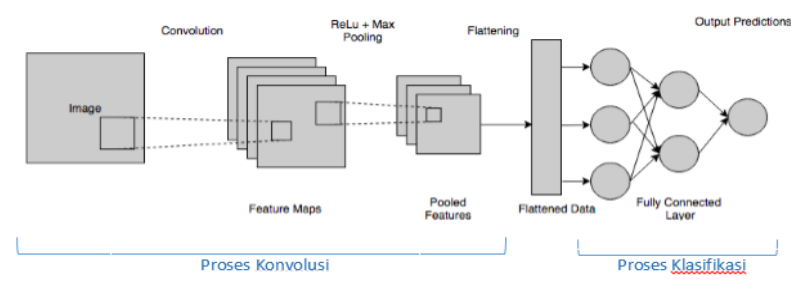

Gambar. 9. Arsitektur CNN

Pada gambar 9 merupakan skema algoritma Convulutional Neural Network (CNN) yang digunakan untuk melakukan penelitian. Pada arsitektur CNN dibutuhkan dua proses untuk CNN perlu dilakukan training data sebelum dapat digunakan untuk klasifikasi. Pada fase training, peneliti mengumpulkan gambar yang berbeda sesuai dengan klasifikasi yang diinginkan. Proses training akan dilakuakn berulang untuk beberapa kali sampai hasil dari perhitungan menjadi lebih optimal untuk melakukan deteksi terhadap polisi tidur. Pada gambar 9 terdapat layer-layer yang dapat digunakan untuk melakukan klasifikasi terhadap suatu gambar 2 dimensi.

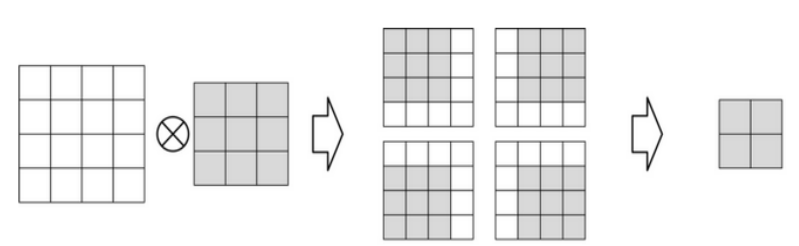

Gambar. 10. Proses Konvolusi CNN

Pada gambar 10 merupakan proses fitur ekstraksi atau konvolusi, yang dibutuhkan sebuah filter gambar yang dapat disebut sebagai kernel untuk dilakukan proses konvolusi yang dengan ukuran tertentu terhadap gambar. Kernel pada metode convolutional neural network, memiliki ukuran yang dapat digunakan antara lain yaitu $3 \times 3,5 \times 5,7 \times 7$ dan sebagainya sesuai dengan penelitian yang dilakukan peneliti.

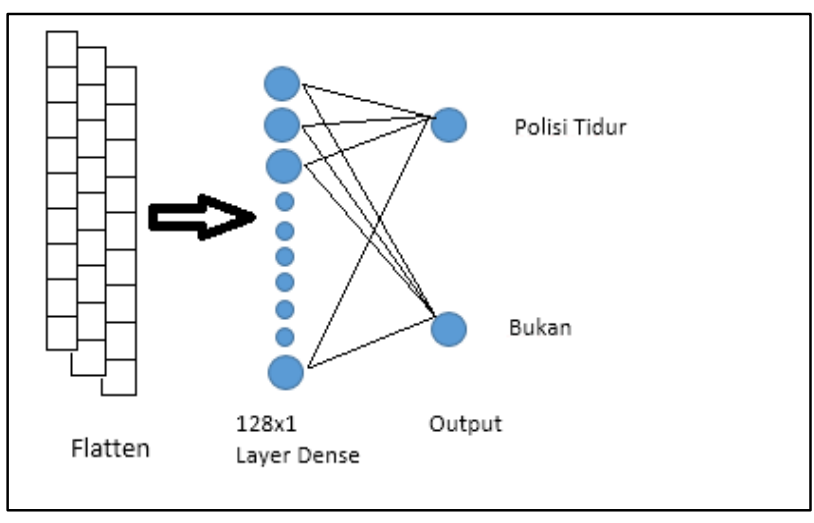

Gambar. 11. Proses Klasifikasi CNN

Pada gambar 11 merupakan gambar proses fully connected pada metode CNN. Pada gambar 11 terdapat tiga layer yaitu input layer, layer dense, dan output layer yang digunakan untuk melakukan klasifikasi. Hasil dari proses konvolusi yang merupakan layer dua dimensi akan diubah menjadi satu dimensi pada proses flatten. Pada layer pertama, pada gambar 11 memiliki 3 channel yaitu dikarenakan gambar input pada penelitian merupakan gambar RGB. Pada hidden layer pertama merupakan layer dense dengan ukuran layer 128x1, ukuran pada layer dense disesuaikan dengan ukuran layer flatten yaitu satu dimensi. Layer input akan dilakukan perbandingan terhadap nilai pixel pada hasil flatten tersebut pada layer dense 128x1. Pada layer terakhir merupakan class objek yang akan digunakan sebagai klasifikasi dalam penelitian, yaitu berupa class jenis polisi tidur atau bukan.

\section{UJI COBA}

Pada penelitian akan dilakukan uji coba terhadap 10 buah video dan 100 gambar pada dataset CNN. Percobaan deteksi dilakukan secara realtime terhadap video yang diinputkan. Pada deteksi, akan diinputkan satu video jalan pada perumahan yang akan dilakukan deteksi, apakah terdapat polisi tidur pada jalan perumahan. Pada perumahan disurabaya memiliki beberapa jenis polisi tidur yang sering dijumpai pada saat melakukan penelitian. Jenis polisi tidur yang dijumpai tersebut antara lain merupakan polisi tidur dengan warna garis hitam putih, garis kuning biru, garis putih kuning dan tanpa warna. Hasil uji coba akan dibahas pada metode anilisis blob terlebih dahulu. 
Pada penelitian, hasil akan dikategorikan sesuai dengan warna pada polisi tidur yang ditemukan. Hasil thresholding dari grayscale gambar input polisi tidur dengan warna putih hitam, kuning biru, kuning putih, kuning hitam, dan tanpa warna memiliki hasil yang berbeda. Pada polisi tidur yang memiliki warna putih memiliki hasil blob yang cenderung lebih banyak dibanding dengan polisi tidur tanpa warna, hal tersebut yang dapat digunakan untuk menampilkan hasil kategori terhadap warna pada penelitian.

TABEL III

HASIL DETEKSI BLOB ANALISIS

\begin{tabular}{lccc}
\hline \hline \multicolumn{1}{c}{ KATEGORI } & Jumlah & Terdeteksi & Gagal \\
\hline Putih Hitam & 21 & 20 & 1 \\
Kuning Biru & 14 & 14 & 0 \\
Kuning Putih & 15 & 11 & 4 \\
Kuning Hitam & 13 & 2 & 11 \\
Tanpa Warna / & 12 & 3 & 8 \\
Pudar & & & \\
\hline \hline
\end{tabular}

Pada tabel 3 merupakan hasil deteksi hanya dilakukan pada polisi tidur dengan warna dan polisi tidur dengan warna pudar atau tanpa warna. Pada hasil ringkasan deteksi blob terdapat lima jenis polisi tidur yang ditemukan pada perumahan, antara lain putih hitam, kuning biru, kuning putih, kuning hitam dan pudar atau tanpa warna. Dapat dilihat anilisis blob dapat mendeteksi polisi tidur yang memiliki warna yang terang dibanding dengan warna dari background polisi tidur yaitu warna aspal.

TABEL IV

HASIL DETEKSI CNN

\begin{tabular}{cccc}
\hline KATEGORI & Jumlah & Terdeteksi & Gagal \\
\hline Putih Hitam & 21 & 21 & 0 \\
Kuning Biru & 14 & 14 & 0 \\
Kuning Putih & 15 & 13 & 2 \\
Kuning Hitam & 13 & 10 & 3 \\
Tanpa Warna / & 12 & 5 & 7 \\
Pudar & & & \\
\hline
\end{tabular}

Pada tabel 4 merupakan hasil deteksi yang dilakukan pada polisi tidur dengan warna dan warna pudar atau tanpa warna menggunakan metode CNN saja. Pada hasil ringkasan deteksi CNN dilakukan pada lima jenis polisi tidur yang sama pada tabel 3. Dapat dilihat hasil CNN memiliki peningkatan pada polisi tidur pada kategori kuning putih, kuning hitam, dan tanpa warna pada deteksi blob ditabel 3. Hasil dari deteksi polisi tidur pada kedua proses CNN dan analisis blob akan dipadukan, dan dideteksi lagi menggunakan kedua metode yang digabungkan. Hasil deteksi CNN dan analisis blob dapat dilihat pada tabel 5 .

TABEL V

HASIL DETEKSI BLOB ANALISIS DAN CNN

\begin{tabular}{lccc}
\hline \multicolumn{1}{c}{ KATEGORI } & Jumlah & Terdeteksi & Gagal \\
\hline Putih Hitam & 21 & 20 & 1 \\
Kuning Biru & 14 & 14 & 0 \\
Kuning Putih & 15 & 14 & 1 \\
Kuning Hitam & 13 & 10 & 3 \\
Tanpa Warna / & 12 & 6 & 6 \\
Pudar & & & \\
\hline \hline
\end{tabular}

Pada tabel 5 merupakan hasil dari deteksi polisi tidur menggunakan dua metode yaitu anilisis blob dan CNN. Pada hasil percobaan, polisi tidur yang gagal dideteksi lebih sedikit dibanding dengan hasil pada tabel 3 dan tabel 4. Pada hasil tabel percobaan, saat anilisis blob tidak dapat mendeteksi polisi tidur maka proses CNN yang akan menangani deteksi sehingga kegagalan untuk mendeteksi polisi tidur dapat diminimalkan. Pada kategori kelima merupakan polisi tidur dengan warna pudar atau tanpa warna yang juga dideteksi menggunakan metode anilisis blob dan CNN.

TABEL VI

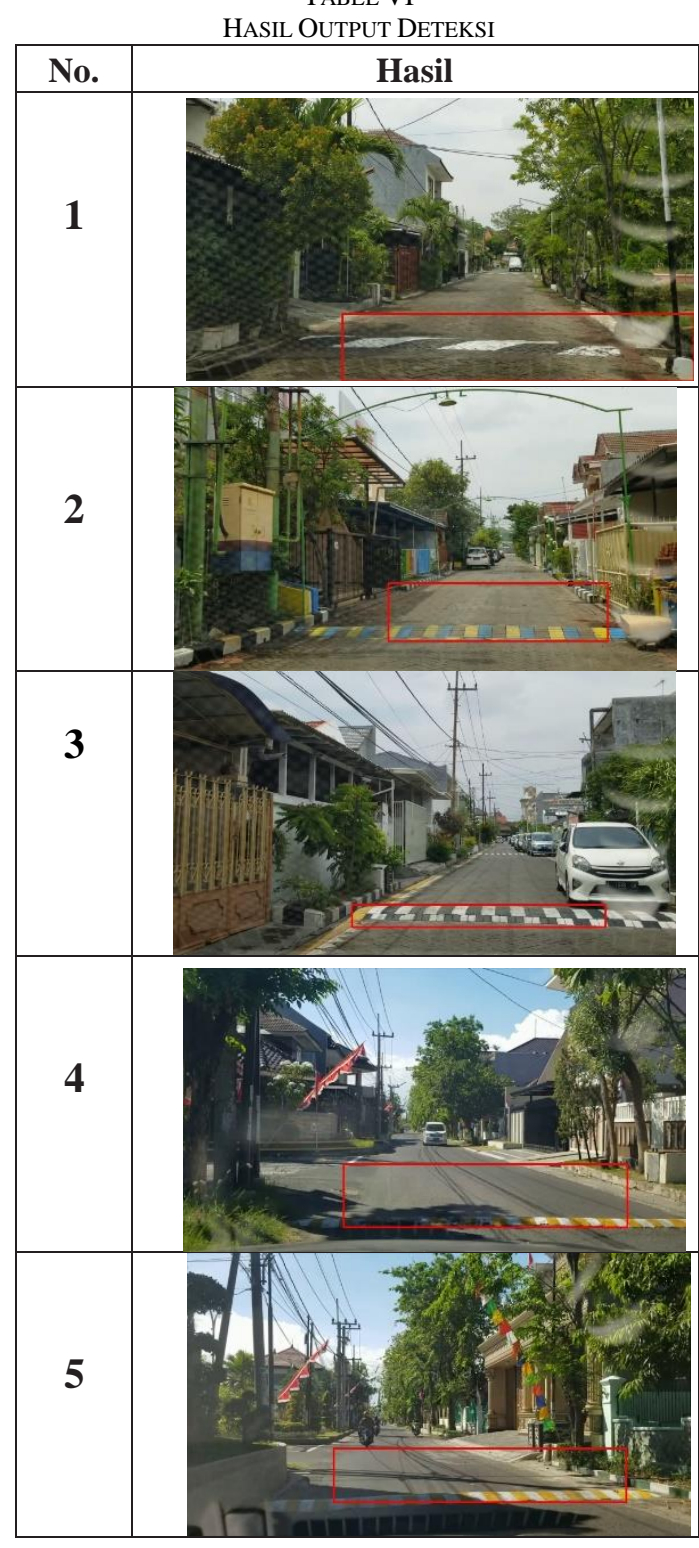

Pada tabel 6 merupakan tabel gambar polisi tidur terkait yang dapat dideteksi oleh metode analisis blob. Dapat dilihat hasil dari labeling polisi tidur dapat membingkai polisi tidur yang tepat berada pada jalan dengan tepat ditengah. Hasil deteksi membuktikan blob analisis memiliki kemampuan yang baik dalam mengenali objek polisi tidur dengan warna yang lebih terang yaitu dalam arti tidak pudar atau tanpa warna 
TABEL VII HASIL OUTPUT DETEKSI

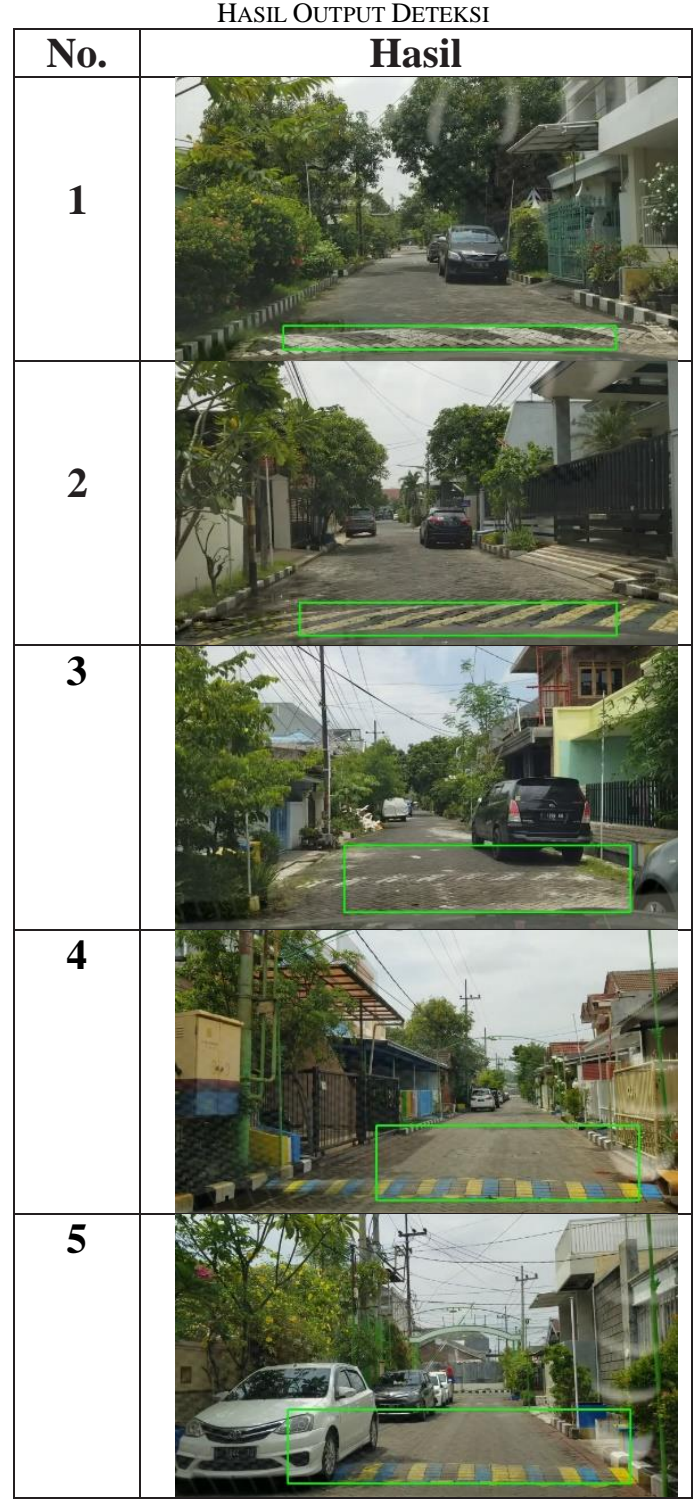

Pada tabel 7 merupakan tabel gambar polisi tidur terkait yang dapat dideteksi oleh metode CNN. Pada hasil deteksi polisi tidur akan ditandai menggunakan persegi panjang berwarna hijau. Pada kelima gambar tersebut merupakan salah satu dari output deteksi terhadap gambar yang melibatkan kelima polisi tidur. Dapat dilihat hasil ketiga merupakan polisi tidur yang pudar yang dapat dideteksi oleh CNN. Hasil deteksi membuktikan CNN memiliki kemampuan yang baik dalam mengenali objek polisi tidur dengan warna yang pudar. Dapat dilihat CNN memiliki tingkat akurasi yang baik untuk mendeteksi polisi tidur yang tidak dapat dideteksi oleh metode blob analisis

\section{KESIMPULAN}

Berdasarkan hasil penelitian Deteksi Polisi Tidur Pada Jalan Menggunakan Anilisis blob dan Convolutional Neural Network, anilisis blob dapat dengan baik mendeteksi objek polisi tidur dengan warna yang lebih terang dari background yaitu aspal. Hasil deteksi memiliki tangkat akurasi yang baik saat CNN dipadukan dengan anilisis blob, sehingga hampir setiap polisi tidur yang ditemui dapat dideteksi. Berikut merupakan poin kesimpulan pada penelitian.
- Anilisis blob memiliki kemampuan yang baik dalam melakukan deteksi terhadap polisi tidur dengan jenis warna yang lebih terang dari background polisi tidur yaitu aspal .

- Dengan adanya CNN yang dipadukan dengan anilisis blob, deteksi polisi tidur dapat mengurangi gagal deteksi yang dikarenakan kelemahan anilisis blob dalam mendeteksi polisi tidur dengan warna pudar/ tanpa warna.

- Tingkat akurasi pada deteksi menggunakan dua metode yaitu anilisis blob dan CNN memiliki tingkat akurasi $76 \%$ untuk mendeteksi polisi tidur dalam lingkup perumahan.

Penelitian masa mendatang akan dikembangkan lebih jauh pada metode yang digunakan, cara memisahkan polisi tidur dari background atau jalan aspal, dan penelitian dapat dikembangkangkan ke tingkat advance driver assistance dimana mobil dapat melambat saat melaju kearah polisi tidur atau adanya pengingat jika akan menabrak polisi tidur dengan kecepatan tinggi.

\section{DAFTAR PUSTAKA}

B. Manikandan and M. Bharathi, "SPEED BREAKER DETECTION USING BLOB ANALYSIS," Int. J. Pure Appl. Math., vol. 118, no. 20, pp. 3671-3677, 2018.

D. P. W., N. Babu C, and T. Srihari, "Real Time Speed Bump Detection Using Gaussian Filtering and Connected Component Approach," Circuits Syst., vol. 07, pp. 2168-2175, 2016, doi: 10.4236/cs.2016.79188.

Z. Hasan, S. N. Shampa, T. R. Shahidi, and S. Siddique, "Pothole and Speed Breaker Detection Using Smartphone Cameras and Convolutional Neural Networks," in 2020 IEEE Region 10 Symposium (TENSYMP), 2020, pp. 279-282.

S. Shah and C. Deshmukh, "Pothole and bump detection using convolution neural networks," in 2019 IEEE Transportation Electrification Conference (ITEC-India), 2019, pp. 1-4.

D. P. W., N. Babu C, and S. Tharumar, "Advance Driver Assistance System (ADAS) - Speed Bump Detection,” 2015, doi: 10.13140/RG.2.1.2412.3285 "Convolutional neural networks based potholes detection using thermal imaging," J. King Saud Univ. Inf. Sci., 2019.

C. Chun and S.-K. Ryu, "Road surface damage detection using fully convolutional neural networks and semi-supervised learning," Sensors, vol. 19, no. 24, p. 5501, 2019.

J. Dharneeshkar, S. A. Aniruthan, R. Karthika, L. Parameswaran, and others, "Deep Learning based Detection of potholes in Indian roads using YOLO," in 2020 International Conference on Inventive Computation Technologies (ICICT), 2020, pp. 381-385.

T. Jia, N. Sun, and M. Cao, "Moving object detection based on blob analysis," in 2008 IEEE International Conference on Automation and Logistics, 2008, pp. 322-325.

[10] H. Maeda, Y. Sekimoto, T. Seto, T. Kashiyama, and H. Omata, "Road damage detection using deep neural networks with images captured through a smartphone," arXiv Prepr. arXiv1801.09454, 2018.

[11] K. Vigneshwar and B. H. Kumar, "Detection and counting of pothole using image processing techniques," in 2016 IEEE International Conference on Computational Intelligence and Computing Research (ICCIC), 2016, pp. 1-4

[12] M. D. Yusuf, R. D. Kusumanto, Y. Oktarina, T. Dewi, and P. Risma, "Blob analysis for fruit recognition and detection," Comput. Eng. Appl. J., vol. 7, no. 1, pp. 23-32, 2018.

[13] V. Varma, S. Adarsh, K. I. Ramachandran, and B. B. Nair, "Real 
time detection of speed hump/bump and distance estimation with deep learning using GPU and ZED stereo camera," Procedia Comput. Sci., vol. 143, pp. 988-997, 2018.

[14] D. K. Dewangan and S. P. Sahu, "Deep learning-based speed bump detection model for intelligent vehicle system using raspberry Pi," IEEE Sens. J., vol. 21, no. 3, pp. 3570-3578, 2020.

[15] K. M. Lion, K. H. Kwong, and W. K. Lai, "Smart speed bump detection and estimation with kinect," in 2018 4th International Conference on Control, Automation and Robotics (ICCAR), 2018, pp. 465-469. 